\title{
Shared Experiences of Proficient English Writers: Criminology Students in Focus
}

\author{
Rhealyn S. Guliman, Baedido M. Timbang, Yennah Marie P. Lagare \\ Bachelor of Arts in English, UM - Matina Campus, Davao City, Philippines \\ rhealynguliman@gmail.com, baedido.timbang@gmail.com,ynnasoo@gmail.com \\ Ana Helena R. Lovitos, Ph. D \\ Adviser, University of Mindanao - Matina Campus, Davao City, Philippines \\ Lovitos.phd@gmail.com
}

\begin{abstract}
This study aimed to explore the shared experiences of proficient Criminology students in English writing. Using the Focus Group Discussion- qualitative method, the researchers interviewed ten Criminology students who obtained the highest scores in the essay writing assessment given to them. The results revealed that the participants knew much about the need for and the importance oflearning the English language. They believed that English is the main language used in terms of global trade and having competence with the language can lead them to a better job in the future. The participants also shared about the difficulties they faced when writing, which includes organization of ideas, vocabularies, correct spellings and proper usage of punctuation marks. Moreover, the participants had their own ways on how to overcome these problems and their motivation had been one of their primary sources to persevere in attaining their desired proficiency.
\end{abstract}

Keywords : English Writing, Criminology Students, University of Mindanao

\section{INTRODUCTION}

Nowadays, the English language is the main medium of communication that is used globally in the academe, business, reports, finances, proposals and so on. The use of the language, however, is not only limited on how it will be said but also on how it will be written.

Pfeifer and Ferree (2006) said that instructors of some colleges and universities across the United States are becoming gradually more aware of a stern but common dilemma: some students have suffered from achieving a good writing skill. In particular, mistakes in grammar, spelling and weakly organized written outputs are highly observed by the instructors. Regardless of the fact that students commit poor writing skills is already observed by school officials and instructors, little has been made to remedy this dilemma. On the other hand, this problem is indeed essential to be addressed because students need to be able to write well in order for them to be successful in their fields. Interestingly, very little formal research has been conducted not only in criminal justice but also in other disciplines that examines either the causes why students cannot write or offers practical answer to remedy the problem.

In Philippine setting, Cabansag (2013) concluded in his study that most of his respondents who are students from the State University of Cagayan Valley are barely proficient in the use of mechanics particularly in capitalization and punctuation. Additionally, most students commit the utmost number of mistakes in the use of verbs and verb tenses and the capitalization rules in their compositions.

However, in the University of Mindanao, being proficient in writing is essential since the university is aiming for quality education. Issues about errors in writing compositions are usually inevitable and criminology students are commonly linked with this problem. Hence, the researchers are interested to figure out how do the participants regard the need for and the importance of learning English language and what they did to attain their proficiency in English writing. This study can give awareness to the teachers and students in determining the strengths and weaknesses of the participants in terms of writing. Also, it can be the basis of the school administrators to implement programs or courses that will address the concerns of this study. 


\subsection{Statement of the Problem}

This study aims to determine the shared experiences of the proficient criminology students in English writing. More specifically, this study sought to answer the following questions:

1. How do the participants regard the need for and the importance of learning English?

2. How did the participants attain their proficiency in writing?

\subsection{Theoretical Lens}

The theories that were used in this study are the cognitive process theory of writing, affective-filter theory and self-determination theory.

The cognitive processes theory of writing developed by Flower and Hayes (1981) claims that writing involves cognitive process in making a composition. The Flower and Hayes (1980, 1981) model verifies the possible difficulties that a writer experienced during the act of composing by examining their rhetorical problems. There are two major components of the "problem-solving activity". First is the rhetorical situation, it includes the audience, topic and assignment, and the second one is the writer's own goals, it involves the reader, the writer's persona, the construction of meaning and the production of formal text. Flower and Hayes (1981) elaborated this theory on four key points. First, the process of writing is best understood as a set of distinctive thinking processes which writers arrange during the act of composing. Second, these processes have hierarchical, highly embedded within any other. Third, the act of composing itself is a goal-directed thinking process, guided by the writer's own increasing network goals. Lastly, writers make their own goals by generating both highlevel goals and supporting sub-goals which represent the writer's developing sense of purpose. Swales (1990) supported that the social dimension is important too when writing. In fact, writing should not be viewed exclusively as an individually-oriented or inner-directed cognitive process but as much as an obtained response to different discourse rules within the respective communities. This theory is anchored in this study because it supports on how the participants cognitive process function when they are asked to make a composition.

Another theory in which this study is also anchored is the Affective Filter Hypothesis. Krashen (1981) stated that this theory deals with the role of "affect" that includes motivation, effect of personality, and other variables that affects on second language acquisition. Gardner and Lambert (1972) supported that the higher the motivation, the higher a learner could easily acquire the second language. Such motivations are indeed effective in the process of learning and acquiring a second language. Krashen (1981) also affirmed that a learner with a higher level of self-esteem and selfconfidence tends to do better in second language acquisition. In this study, this theory places a vital part in helping the researchers identify the motivational aspects that the participants have in acquiring English proficiency in terms of writing.

On the other hand, since motivation is one of the factors that greatly affects on acquiring English writing proficiency of the participants, the researchers make use of the Self-Determination Theory developed by Deci and Ryan (1985). This theory is an approach to human motivation and personality, and is concerned with supporting the intrinsic or natural tendencies to behave in effective and good ways. This theory is divided into two: these are intrinsic motivation and extrinsic motivation. Intrinsic motivation refers to doing an activity because it is found pleasurable and appealing while extrinsic motivation refers to doing an activity because it leads to divisible outcome.

\section{METHOD}

\subsection{Research Design}

This study used a qualitative research design in order to know the shared experiences of the proficient fourth year Criminology students in English writing in the University of Mindanao. A qualitative research was defined by Shank (2002) as a form of systematic empirical inquiry into meaning. San Jose (2012) supported that qualitative method is more dynamic compared to the structured format of the quantitative method.

The researchers chose to use the Focus Group Discussion (FGD) method of qualitative research for direct and depth response from the participants. Wong (2008) defined FGD as a methodological process in which a small group of participants were gathered to discuss a specific topic or issue to generate information. Kitzinger (1994) supported that FGD is a form of qualitative research method in 
which an interviewer (moderator) asks the participants some specific questions about a particular topic or issue in a group discussion. Focus groups provide the added dimension of the interactions among members unlike individual interviews. In conducting the focus group, the emphasis should be placed on the interaction among the group members. Instead of the moderator asking questions, the members of the group are rather encouraged to communicate with one another, exchanging ideas and comments on each other's experiences or points of view. In this study, we gathered the participants to a Focus Group Discussion for deep interaction between the interviewers and the interviewees. In this case, we could demonstrate a substantial way of gathering information from the participants

\subsection{Rese arch Participants}

The participants of the study were the fourth year criminology students in the Criminal Justice Education Program of the University of Mindanao, who were officially enrolled in the first semester of the school year 2015-2016. The researchers chose three classes of fourth year students to be asked to write a composition consisting of two hundred (200) words. Out of these three classes the researchers have chosen the proficient English writers based on their works. The researchers evaluated and analyzed their written outputs by using the ESL composition profile of Jacobs, Zinkgraf, Wormouth, Hartfiel and Hughey (1981). After evaluating and analyzing, the ten (10) qualified students who attained the highest proficiency in English writing were examined and interviewed through Focus Group Discussion (FGD). The result of the essay writing activity is summarized in a table presented in the Appendix A section.

AppendixA. ESL Composition Profile of Criminology Students (Results)

\begin{tabular}{|c|c|c|c|c|c|c|}
\hline $\begin{array}{l}\text { Written } \\
\text { Outputs }\end{array}$ & \begin{tabular}{|l} 
Contents \\
(30)
\end{tabular} & \begin{tabular}{|l|} 
Organization \\
$(\mathbf{2 0})$
\end{tabular} & \begin{tabular}{|l} 
Vocabulary \\
(diction) (20)
\end{tabular} & \begin{tabular}{|l|} 
Language \\
Use (grammar) (25)
\end{tabular} & \begin{tabular}{|l} 
Mechanics \\
(5)
\end{tabular} & $\begin{array}{l}\text { Total } \\
(\mathbf{1 0 0})\end{array}$ \\
\hline EWP1 & 26 & 16 & 17 & 18 & 4 & 81 \\
\hline EWP2 & 30 & 18 & \begin{tabular}{|l|}
18 \\
\end{tabular} & 23 & 2 & 91 \\
\hline EWP3 & 27 & \begin{tabular}{|l|}
18 \\
\end{tabular} & \begin{tabular}{|l|}
18 \\
\end{tabular} & 22 & 4 & \begin{tabular}{|l|}
89 \\
\end{tabular} \\
\hline EWP4 & 26 & 15 & 15 & \begin{tabular}{|l|}
19 \\
\end{tabular} & 4 & 79 \\
\hline EWP5 & 25 & 16 & \begin{tabular}{|l|}
16 \\
\end{tabular} & \begin{tabular}{|l|}
18 \\
\end{tabular} & 4 & 79 \\
\hline EWP6 & 27 & 17 & 14 & 18 & 3 & 79 \\
\hline EWP7 & 23 & 13 & 14 & 17 & 3 & 80 \\
\hline EWP8 & 25 & 16 & 17 & 20 & 4 & 82 \\
\hline EWP9 & 25 & 17 & 17 & 20 & 4 & 83 \\
\hline EWP1O & 26 & 16 & \begin{tabular}{|l|}
17 \\
\end{tabular} & 22 & 4 & 85 \\
\hline EWP11 & 25 & 15 & 14 & 15 & 3 & 72 \\
\hline EWP12 & 22 & 14 & 15 & 18 & 3 & 72 \\
\hline EWP13 & 22 & 15 & 13 & 17 & 4 & 71 \\
\hline EWP14 & 25 & 15 & 15 & 17 & 3 & 75 \\
\hline EWP15 & 23 & 15 & 14 & \begin{tabular}{|l|}
18 \\
\end{tabular} & 4 & 74 \\
\hline EWP16 & 21 & 13 & 13 & \begin{tabular}{|l|}
17 \\
\end{tabular} & 3 & 67 \\
\hline EWP17 & 20 & 13 & 13 & 11 & 3 & 60 \\
\hline EWP18 & 26 & 13 & 15 & 12 & 3 & 61 \\
\hline EWP19 & 17 & 12 & 13 & 13 & 3 & 58 \\
\hline EWP20 & 20 & 13 & 13 & 12 & 3 & 61 \\
\hline EWP21 & 16 & 9 & 9 & 11 & 2 & 47 \\
\hline EWP22 & 20 & 13 & 13 & 16 & 3 & 65 \\
\hline EWP23 & 21 & 13 & 13 & 15 & 2 & 64 \\
\hline EWP24 & 21 & 13 & 13 & 16 & 3 & 66 \\
\hline EWP25 & 19 & 13 & 13 & 15 & 3 & 63 \\
\hline EWP26 & 22 & 13 & 15 & 15 & 3 & 68 \\
\hline EWP27 & 17 & 10 & 8 & 6 & 2 & 43 \\
\hline EWP28 & 20 & 12 & 12 & 11 & 3 & 58 \\
\hline EWP29 & 18 & 12 & 11 & 11 & 3 & 55 \\
\hline EWP30 & 16 & 14 & 10 & 11 & 3 & 54 \\
\hline EWP31 & 13 & \begin{tabular}{|l|}
19 \\
\end{tabular} & \begin{tabular}{|l|}
10 \\
\end{tabular} & 9 & 2 & 43 \\
\hline EWP32 & 13 & 7 & 7 & 5 & 2 & 34 \\
\hline EWP33 & 13 & 7 & 7 & 5 & 2 & 34 \\
\hline EWP34 & 15 & 10 & 8 & 11 & 3 & 47 \\
\hline EWP35 & 21 & 14 & \begin{tabular}{|l|}
10 \\
\end{tabular} & 12 & 3 & 60 \\
\hline EWP36 & 21 & 14 & 14 & 15 & 3 & 67 \\
\hline
\end{tabular}


Rhealyn S. Guliman et al.

\begin{tabular}{|c|c|c|c|c|c|c|}
\hline EWP37 & 20 & 12 & 13 & 13 & 3 & 61 \\
\hline EWP38 & 18 & 13 & 13 & 10 & 2 & 56 \\
\hline EWP39 & 20 & 13 & 13 & 15 & 3 & 64 \\
\hline EWP40 & 16 & 9 & 10 & 10 & 2 & 47 \\
\hline EWP41 & 21 & 13 & 13 & 17 & 2 & 66 \\
\hline EWP42 & 16 & 13 & 13 & 12 & 3 & 57 \\
\hline EWP43 & 17 & 13 & 13 & 14 & 3 & 60 \\
\hline EWP44 & 14 & 9 & 12 & 11 & 2 & 48 \\
\hline EWP45 & 19 & 13 & 13 & 16 & 3 & 64 \\
\hline EWP46 & 16 & 10 & 9 & 11 & 2 & 48 \\
\hline EWP47 & 20 & 9 & 8 & 9 & 2 & 48 \\
\hline EWP48 & 20 & 14 & 13 & 12 & 3 & 62 \\
\hline EWP49 & 19 & 13 & 13 & 16 & 3 & 64 \\
\hline EWP50 & 15 & 12 & 13 & 13 & 3 & 56 \\
\hline EWP51 & 17 & 11 & 13 & 12 & 3 & 56 \\
\hline EWP52 & 16 & 10 & 11 & 10 & 3 & 50 \\
\hline EWP53 & 18 & 10 & 10 & 3 & 2 & 53 \\
\hline EWP54 & 15 & 9 & 10 & 7 & 2 & 43 \\
\hline EWP55 & 17 & 12 & 13 & 12 & 3 & 57 \\
\hline EWP56 & 16 & 13 & 13 & 10 & 3 & 55 \\
\hline EWP57 & 9 & 9 & 10 & 9 & 2 & 39 \\
\hline EWP58 & 21 & 13 & 13 & 15 & 3 & 55 \\
\hline EWP59 & 23 & 13 & 13 & 17 & 2 & 68 \\
\hline EWP60 & 24 & 14 & 11 & 12 & 3 & 64 \\
\hline EWP61 & 18 & 13 & 12 & 13 & 3 & 59 \\
\hline EWP62 & 23 & 15 & 14 & 18 & 4 & 74 \\
\hline EWP63 & 25 & 15 & 15 & 17 & 3 & 75 \\
\hline EWP64 & 22 & 15 & 13 & 17 & 4 & 71 \\
\hline EWP65 & 22 & 14 & 15 & 18 & 3 & 72 \\
\hline EWP66 & 25 & 15 & 14 & 15 & 3 & 72 \\
\hline
\end{tabular}

\subsection{Research Instrument}

The written outputs of the fourth year criminology students in the University of Mindanao served as the first way of determining the primary subjects of this study. The outputs of the participants served as the source of selecting the ten proficient students based on their attained scores. The written outputs were evaluated using the ESL Composition profile of Jacobs,et.al (1981) which is presented in the Appendix B section. Consequently, FGD was conducted to gather information directly from the ten participants. The researchers assured that the information gathered were validated and approved by the participants to be analyzed and studied.

AppendixB. ESL COMPOSITION PROFILE by Jacobs, Zinkgraf, Wormouth, Hartfiel\&Hughey (1981)

\begin{tabular}{|c|c|c|}
\hline \multicolumn{3}{|c|}{ ESL COMPOSITION PROFILE } \\
\hline \multicolumn{3}{|c|}{ STUDENT } \\
\hline SCORE & LEVEL & COMMENTS \\
\hline \multirow{4}{*}{ 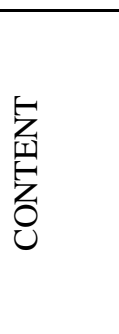 } & $30-27$ & $\begin{array}{l}\text { EXCELLENT TO VERY GOOD: knowledgeable } \bullet \text { substantive } \bullet \text { thorough } \\
\text { development of thesis } \bullet \text { relevant to as signed topic }\end{array}$ \\
\hline & $26-22$ & $\begin{array}{l}\text { GOOD TO AVERAGE: some knowledge of subject } \bullet \text { adequate range } \bullet \text { limited } \\
\text { development of thesis } \bullet \text { mostly relevant to topic, but lacks detail }\end{array}$ \\
\hline & $21-17$ & $\begin{array}{l}\text { FAIR TO POOR: limited development of subject } \bullet \text { little substance } \bullet \text { inadequate } \\
\text { development of topic }\end{array}$ \\
\hline & $16-13$ & $\begin{array}{l}\text { VERY POOR: does not show knowledge of subject } \bullet \text { non-substantive } \bullet \text { not Pertinent } \\
- \text { OR not enough to evaluate }\end{array}$ \\
\hline \multirow{4}{*}{ 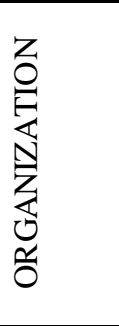 } & $20-18$ & $\begin{array}{l}\text { EXCELLENT TO VERY GOOD: fluent expression } \bullet \text { ideas clearly stated supported } \\
\bullet \text { succinct } \bullet \text { well-organized } \bullet \text { logical sequencing } \bullet \text { cohesive }\end{array}$ \\
\hline & $17-14$ & $\begin{array}{l}\text { GOOD TO AVERAGE: somewhat choppy } \bullet \text { loosely organized but main } \\
\text { ideas stand out } \bullet \text { limited support } \bullet \text { logical but incomplete sequencing }\end{array}$ \\
\hline & $13-10$ & $\begin{array}{l}\text { FAIR TO POOR: non-fluent } \bullet \text { ideas confused or disconnected } \bullet \text { lacks } \\
\text { logical sequencing and development }\end{array}$ \\
\hline & $9-7$ & $\begin{array}{l}\text { VERY POOR: does not communicate } \bullet \text { no organization } \bullet \text { OR not enough to } \\
\text { evaluate }\end{array}$ \\
\hline
\end{tabular}




\begin{tabular}{|c|c|c|}
\hline \multirow{4}{*}{ 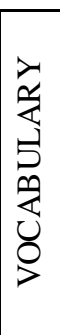 } & 20-18 & $\begin{array}{l}\text { EXCELLENT TO VERY GOOD: sophisticated range } \bullet \text { effective } \text { word/idiom } \\
\text { choice and usage } \bullet \text { word form mastery } \bullet \text { appropriate register }\end{array}$ \\
\hline & \begin{tabular}{|l|}
$17-14$ \\
\end{tabular} & $\begin{array}{l}\text { GOOD TO AVERAGE: adequate range } \bullet \text { occasional errors of word/idiomform, } \\
\text { choice, usage but meaning not obscured }\end{array}$ \\
\hline & \begin{tabular}{|l|}
$13-10$ \\
\end{tabular} & $\begin{array}{l}\text { FAIR TO POOR: limited range } \bullet \text { frequent errors of } \text { word/idiom form, } \\
\text { choice, usage } \bullet \text { meaning confused or obscured }\end{array}$ \\
\hline & \begin{tabular}{|l|}
$9-7$ \\
\end{tabular} & $\begin{array}{l}\text { VERY POOR: essentially translation } \bullet \text { little knowledge of English vocabulary, } \\
\text { idioms, word form } \bullet \text { OR not enough to evaluate }\end{array}$ \\
\hline \multirow{4}{*}{ 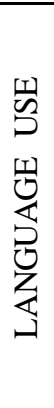 } & $25-22$ & $\begin{array}{l}\text { EXCELLENT TO VERY GOOD: effective complex constructions } \bullet \text { few errors of } \\
\text { agreement, tense, number, word order/function, articles, pronouns, prepositions }\end{array}$ \\
\hline & \begin{tabular}{|l}
$21-18$ \\
\end{tabular} & $\begin{array}{l}\text { GOOD TO AVERAGE: effective but simple constructions } \bullet \text { minor problems in } \\
\text { complex construction } \bullet \text { several errors of agreement, tense, number, word } \\
\text { order/function, articles, pronouns, prepositions but meaning seldom obscured }\end{array}$ \\
\hline & \begin{tabular}{|l|}
$17-11$ \\
\end{tabular} & $\begin{array}{l}\text { FAIR TO POOR: major problems in simple/complex construction } \bullet \text { Frequent errors } \\
\text { of negation, agreement, tense, number, wordOrder/function, articles, pronouns, } \\
\text { prepositions and/or fragments, run-ons, deletions } \bullet \text { meaning confused or obscured }\end{array}$ \\
\hline & \begin{tabular}{|l|}
$10-5$ \\
\end{tabular} & $\begin{array}{l}\text { VERY POOR: virtually no mastery of sentence construction rules } \bullet \text { Dominated by } \\
\text { errors } \bullet \text { does not communicate } \bullet \text { OR not enough to Evaluate }\end{array}$ \\
\hline \multirow{4}{*}{ 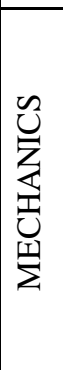 } & 5 & $\begin{array}{l}\text { EXCELLENT TO VERY GOOD: demonstrates mastery of conventions } \bullet \text { few errors } \\
\text { of spelling, punctuation, capitalization, paragraphing }\end{array}$ \\
\hline & 4 & $\begin{array}{l}\text { GOOD TO AVERAGE: occasional errors of spelling, punctuation, capitalization, } \\
\text { paragraphing but meaning not obscured }\end{array}$ \\
\hline & \begin{tabular}{|l}
3 \\
\end{tabular} & $\begin{array}{l}\text { FAIR TO POOR: frequent errors of spelling, punctuation, capitalization, } \\
\text { paragraphing } \bullet \text { poor handwriting } \bullet \text { meaning confused or obscured }\end{array}$ \\
\hline & 2 & $\begin{array}{l}\text { VERY POOR: no mastery of conventions } \bullet \text { dominated by errors of spelling, } \\
\text { punctuation, capitalization, paragraphing } \bullet \text { handwriting illegible } \bullet \text { OR not enough to } \\
\text { evaluate }\end{array}$ \\
\hline
\end{tabular}

Total Score Reader Comments

\subsection{Data Gathering}

To make this study possible, a letter asking permission from the Dean of the College of Criminal Justice Education was sent to allow the researchers to conduct a study and let the criminology students make a two hundred (200) word composition.

After getting the approval of the Dean, the researchers preceded asking the participants to make their compositions together with their approval that their written outputs will be studied but remains confidential. There were three classes of fourth year criminology students that were asked to participate in the essay writing activity. Then, after the submission of the students' written outputs, the researchers compiled, analyzed and evaluated the papers accordingly. During the writing activity, the researchers made sure that the contact numbers of the participants were asked. The participants were also informed that if their outputs will be qualified, they will be contacted for a group interview.

In analyzing, the researchers applied the ESL composition profile of Jacobs, Zinkgraf, Wormouth, Hartfiel and Hughey (1981) in selecting the ten (10) qualified proficient English writers. These ten students were called and interviewed through a Focus Group Discussion.

Furthermore, the construction of the FGD guide questions is in line with the research questions of this study. It focused on how the participants regard the need for and the importance of learning English, and how they attained their proficiency. However, it also includes their primary reasons why they have to be proficient in writing and the strategies they used to overcome their difficulties when writing with the use of English language. The FGD guide questions were generated to serve as a guide for the conversation within the participants and to get the basic information about their English writing proficiency.

Moreover, the validation of the FGD guide questions was carefully done by the three expert validators of the Language department before it was used to conduct the study. This is to ensure that the questions would not harm the participants but rather to extract the information that were considered useful in this study.

Before the interview starts, the researchers explained to the participants about the main purpose of the research and handed them the consent letters as a confirmation of their involvement in the study. Then, the researchers made use of voice recorders to record every detail that the participants are 
saying during the discussion. Finally, the researchers used transcription of information that will serve as a primary source in detailing and analyzing the discussion.

\subsection{Trustworthiness}

As the field of qualitative research increases, social and behavioural scientists review on the validity of studies that use such methodology. Through this, qualitative researchers used of various validation strategies to make their studies reliable and accurate.

In order to show validity and reliability of this study, trustworthiness and credibility were needed to test. In achieving the trustworthiness and credibility during the collection of data, the researchers purposely used Lincoln and Guba's (1985) criteria in verifying the information given by the participants. The four criteria in evaluating interpretive research work are credibility, transferability, dependability, and conformability.

Bradley (1993) defines credibility as the sufficient representation of the constructions of the social world under study. Lincoln and Guba (1985) recommended a set of activities that would help improve the credibility of research results: prolonged engagement in the field, persistent observation, triangulation, negative case analysis, checking interpretations against raw data, peer debriefing, and member checking. In this study, we make sure that the collected compositions during the actual writing of participants were the same with the information given in this study. All the compositions gathered from the participants were analyzed and evaluated accordingly. We make sure that the participants were comfortable for the reason that good rapport was established between us and the participants. Through that, we are confident enough that the participants would give their trust to us and would write and say candidly their ideas without being pressured.

Zhang and Wildemuth (2009) describe transferability as the degree to which the researcher's working hypothesis can be applied to another context. It is not the researcher's task to provide an index of transferability; rather, he or she is responsible for providing sets of gathered information and descriptions that are rich enough so that other researchers are able to make judgments about the findings' transferability to different settings or contexts. Transferability was realized in this study by presenting detailed information of the settings and other information about the participants of the study being discussed in the research participants section of the study. Moreover, the output of the study would also be used by other researchers for any further research. Also, the researchers incorporated in this study some of the documents that were utilized in order to gather the data from the participants and made it sure to be available upon request by the other researchers.

Bradley (1993) defines dependability as the coherence of the internal process and the way a researcher accounts for changing conditions in the phenomena. We used the cognitive processes theory of writing developed by Flower and Hayes (1981), Affective Filter theory by Krashen(1981), SelfDetermination theory by Deci and Ryan (1985) and supported by different ideas of varied authors. The concepts used in this study were obtained from the assertions of dependable authors of books and journals that are related to English writing proficiency. Additionally, the research questions of this study were verified and validated by the three (3) expert validators to ensure the outcomes of the research and the transcribed group interview were verified by the participants. Conformability is characterized as the point to which the characteristics of the gathered information, as speculated by the researcher, can be confirmed by others who read or review the research outcome. In this study, we make sure that findings were from the result of expertise, ideas and knowledge of the participants and not from our own preferences.

\subsection{Scope and Limitation}

This study was conducted accompanied by its scope and limitations to demonstrate focus on a specific topic and to show a clear scope. The focus of this study is the shared experiences of proficient Criminology students in English writing. In order to achieve this aim, the researchers inquired about how the participants regard the need for and the importance of learning English and how they attained their proficiency.

Furthermore, the participants are ten (10) officially enrolled fourth year criminology students who got the highest scores in the essay writing activity that was given by the researchers. Wong (2008) supported that most focus groups usually consist of between six to twelve people. The group should not be so large as to prevent adequate involvement by most participants nor should it be so small that it fails to present important greater coverage than that of an individual interview. 
On the other hand, the research is only limited to the fourth year criminology students who are enrolled in the University of Mindanao A.Y. 2015-2016. Since the study aspires to cover the shared experiences of proficient Criminology students in English writing the researchers only include the ten (10) fourth year criminology students who attained the highest scores from the essay writing activity. Moreover, the study only used qualitative focus group discussion as the research design; and with regard to the gathering of data from the participants, the information were collected through a focus group interview with the help of two (2) voice recorders. Additionally, the analysis of the data gathered was only bordered to qualitative type of research in which only the shared experiences of the proficient criminology students in English writing, insights on the need for and importance of learning English and strategies in attaining such proficiency is covered.

\section{ReSULTS AND Discussion}

\subsection{The Need for and the Importance of Learning English Language}

This study found out that all of the participants appreciated the importance of learning the English language. For instance, EWP1 sees the English language as an international language because it is widely used to communicate all over the world. EWP8 added that learning the English language is important for us to be able to communicate with other people around the world. Learning to communicate in English is important because it connects people around the world and it is necessary to enter and eventually succeed in major English speaking countries. Indeed, working knowledge of the English language can give many opportunities in the field of international markets and regions (Inlinguamalta.com, 2015). As we all know, English language has been the primary language used in international affairs. This is the reason why the participants really valued the worth of learning English. On the other hand, EWP1 appreciated the advantage of having good command in English since it will give him the opportunity to get a better job. This is true since knowing English is a helpful tool to enter job and employment opportunities in global markets. For instance, multilateral institutions and agencies in the world such as New York, Vienna and Geneva recruit professionals with multilingual skills and also expected to have good English skills. Also, there are numerous job opportunities that are offered for those who can understand and communicate in English. Reep (2003) added that writing is important no matter what your job is. It is because you need to communicate your technical knowledge to others either outside or inside of the organization where you belong. EWP5 added that to be able to accommodate and communicate with the tourists who visit our country, English is a helpful tool to entertain them. As a matter of fact, aside from global trade and commerce, English is also widely used in tourism to be able to interact and engage with tourists and immigrants.

In connection, the study revealed that all of the participants believed that being competent in English is important to communicate with people not only in locally but also internationally. In terms of proficiency in writing, this study found out that the participants give positive feedbacks in determining the significance of writing proficiency. As criminology students, the participants knew that writing plays a significant aspect in their field because in the future they are expected to make reports and other documents that really require efficient writing. For instance, EWP3 said that their job in the future includes writing reports. He also added that their reports must be presented in English and must follow the rules of proper grammar and construction of sentences. Moreover, EWP1 asserted that they have to be careful with every detail and word that they will write because every mistake they made really matters. This is supported by Roufa (2015) when he said that writing is fundamental in every phase of a criminologist's career. Thus, the ability to write effectively is not only a valuable skill, but an essential one. To become successful and effective in their profession, criminology students should start working on their abilities to use the written language. On the other hand, EWP7 stated that as criminology students, they should be proficient in writing and as much as possible they should avoid committing mistakes. In this way, they will not be a burden in the organization. This simply means that the participants valued the name of the organization where they belong. Hence, the study revealed that the participants knew that English writing is a significant factor in their chosen field.

Moreover, the ability to write effectively is a must in every career option in criminology. To become an efficient writer, one must consider the factors that are needed to be learned. EWP 3 shared that he wants to learn more terms and words to suffice his ideas when he is writing for him to express it. Jose (1986) defined vocabulary as the supply of words that are use whether in speaking or writing. How to 
consider someone as a good report writer is by looking on his vocabulary as a basis. If the supply of words is limited, it only means that the development of good habits of wide reading of literatures in the field of police and criminology is not well established. The use of a dictionary is helpful to improve one's vocabulary because it contains a good set of useful information aside from definitions. Thus, wide reading of literature and constant consultation of dictionary is a good habit to improve one's vocabulary. On the other hand, EWP6, EWP8, EWP9 and EWP10 added that they all want to learn more on how to construct correct sentences and to organize their ideas. In police report writing, especially in investigative reporting, the construction and length of sentences varied. Reports should be written in the past tense since crimes are investigated after it is done, and reports are made after the investigation. A writer should pay attention on verbs, pronouns, adjectives and adverbs to make sure that the sentences in the report are correct. In terms of organizing ideas, criminology students should be clear, simple and objective in making their written reports. Hence, a written report should follow certain standards in writing. It should be submitted in a proper form to satisfy the needs of the police organization, law enforcement agencies and individuals. EWP1, EWP2, EWP4 and EWP5 stated that they want to learn more about the proper usage of punctuation marks. The complete meaning of a sentence depends on the punctuation that is used in a sentence. An error in punctuation can suggest a completely different meaning to the one that is intended. This is the reason why punctuation marks really matters because it gives sense to what is written. Miller and Whitehead (2011) said that punctuation is one of the more helpful and logical characteristics of grammar and can also be a cause of problem when it results to over punctuation. In connection, the study revealed that the participants want to learn more terms, to learn how to organize ideas and to learn how to use punctuation marks correctly in writing.

\subsection{Attaining the Proficiency in English Writing}

To increase competence in English, it is a good idea to know the most effective strategies to be applied. EWP1, EWP6, EWP7, EWP8, EWP9 and EWP10 stated that they usually read English books to increase their competence in the language. This is supported by Langan (2010) that to be a skillful writer, one should consider the importance of skillful reading. Indeed, reading is considered as a helpful tool in improving one's skill in English language. When reading, it helps widen the vocabulary of a particular reader and gain a lot of ideas from different authors. EWP1, EWP4 and EWP8 added that watching English movies helped them to increase their competence. Watching English films or TV programs is a good way to broaden your vocabulary (caes.hku.hk,2015). It also improves your listening comprehension and polishes your speaking skills. Watching a video on a computer, smart phone, tablet or laptop is also a very convenient learning activity. Another advantage of watching films with native English speakers is that you will be able to know phrases that you don't usually learn in school. EWP1 and EWP7 answered that they usually surf the internet to search for unfamiliar words and to enrich their vocabulary. Anderson (2003) said that computers and Internet play an increasingly vital role in the learning of second language learners around the world. Online reading serves as a source of input for many second language readers. Additionally, Leu (2002) stressed out that the Internet has entered the classrooms faster than books, television or any other technology for communication and information purposes. Since the use of computer is increasing, the need to train language learners how to read online should also increase. Coiro (2003) points out that electronic text establish new challenges that have a great effect on one's ability to understand what he or she reads. On the other hand, EWP1, EWP2, EWP3, EWP5 and EWP10 responded that they use English language daily to help improve their proficiency with the language. Conversing daily with friends and fellow students in English is an effective strategy to help enhance English skills (Fluentu.com,2015). For the participants, if they keep on talking with the use of English language they will be able to learn quickly because they are interacting with each other. EWP9 added that she habitually listens to people who speak in English to enhance her competence because she seems unsatisfied if she was not able to hear peoples' conversation. Kupper (1989) asserted that listening comprehension has become the basis of second language acquisition and instruction which focus on the beginning levels of second language proficiency. Thus, the participant manifested that she learns more by listening.

Difficulty is part of learning. It is inevitable to encounter difficulties specifically in terms of writing. A hardworking learner needs to exert more effort in order to overcome these difficulties. EWP1and EWP2 answered that they have problems when it comes to grammar and coherence when making a composition. McDonald and Salomone (1996) stated that to improve the clarity of your writing, you 
have to work on coherence because it involves clarifying the relationship between ideas. Coherence clearly relates your ideas or sentences to each other or to the central idea of your composition. In other words, when your ideas were coherent they are easy to understand. Additionally, Reep (2003) stated that when sentences ensue in a sequence that supports one central idea, a paragraph is considered coherent. Some devices like transitional or connecting words and phrases help to attain coherence by showing the relationships of ideas and by creating smooth flow of sentence. Hence, the participants want to develop their skills in connecting their ideas to produce a comprehensible type of writing. On the other hand, EWP1, EWP3, EWP6, EWP7, EWP8, EWP9 and EWP10 all agreed that organizing their ideas is their major problem. Kanar (1998) explained that a good writing follows organized steps. Understanding an organized paragraph and essay helps to determine relationship among ideas. A writing skill increases when the ideas are well-structured, and is easy for the readers to comprehend. Conversely, EWP2, EWP4 and EWP5 said that spelling is one of their main difficulties. Miller and Whitehead (2011) affirmed that poor spelling can also lead to confusion and convey wrong information to the readers. Required standards in the field of work should be met and followed by the writers. In this case, the participants are aware that spelling is an important factor to practice and enhance because they already knew that writing reports is part of their job in the future and spelling should be strictly observed. This scenario is explained on the cognitive processes theory of writing developed by Flower and Hayes (1981) which claims that writing involves cognitive process in making a composition. Indeed, the participants involve thinking when they are writing because they already have the plans in their mind about the things that they will include in their compositions. Based on the difficulties they encountered, the participants' cognitive skills are being tested. This simply means that the participants are conscious on every detail that they write. They are aware on their difficulties and weaknesses in making their written outputs.

In order to overcome problems in writing, the participants have their own ways on how to unlock their difficulties. This is supported by Krashen's (1981) Affective Filter Theory which suggests that the role of "affect" in acquiring a language includes motivation, effect of personality and other variables. EWP1, EWP2, EWP4 and EWP5 said that practice is one of the most effective ways to overcome difficulties. They tend to write and write to practice their skills and exercise their minds. To make writing as a daily task results to a new habit. Writing daily will also develop skills in English and will also soon become something to be look forward for (English-tonight.com,2015). A significant development will never be evident if there is no dedication towards becoming a better writer in English. On the other hand, EWP6 shared that he frequently asks for an advice to his classmates for peer assessment to his output. Topping (2003) stated that peer assessment of writing might include giving overall feedback, or going beyond to very specific feedback for probable improvement. It can focus on the whole written product, or components of the writing process. Conversely, EWP10 added that he review his work always every time he is done writing. In that way, he can correct his grammar or erroneous sentences in his written output. Self-assessment is a way of arrangement for learners to consider and identify the level, value or quality of their own works. Its purpose is to engage learners as active participants in their own learning and promote learners' reflection on their own learning processes, ways and customs.

Being inspired to improve has a big contribution to people who aims for their betterment. This is explicated by Self-Determination Theory developed by Deci and Ryan (1985) which is an approach to human motivation and personality, and is concerned with supporting the intrinsic or natural tendencies to behave in effective and good ways. EWP1, EWP2, EWP4, EWP5, EWP8 and EWP10 stated that their inspiration to be proficient in writing is themselves. Ryan and Deci (2000) defined intrinsic motivation as the act of doing something for its innate satisfactions rather than for some divisible consequence. When a person is intrinsically motivated, he is moved to do something for the challenge or fun involved rather than because of external prods, demands, or rewards. In this case, the participants are motivated to be proficient for their own good. On the other hand, EWP6 shared that his family and colleagues motivates him to learn and improve his writing skills while EWP3 said that he considered his professors as his inspiration to be proficient. EWP7 and EWP8 also answered that their future profession keeps them to strive harder in learning to write efficiently. This kind of motivation is called extrinsic motivation which refers to a construct that every time an activity is done in order to achieve some divisible outcome. Thus, the participants preferred to be motivated by the people, situation and things around them. 


\section{CONClusion AND IMPliCATION FOR Practice}

\subsection{Conclusion}

The need for and the importance of learning English has been one of the participants' priorities since they are aware that it is very useful in their future field. Based on their responses the participants have attained concept that being proficient in English is an advantage in the real world scenario. Since they knew that their written outputs will greatly affect the credibility of their profession as a future police officer, they desired to learn more on how to write effectively. Through this information, we come into the idea that their realization on the importance of learning English language has been their guide to be more motivated in enhancing their skills especially in writing.

In connection, the participants have their own strategies to increase their competence in writing. This includes reading English books, watching English movies, internet surfing, using the English language daily and listening to people who speaks in English. However, the participants also shared their difficulties when writing. This is a clear indication that they knew by themselves that there are things which they need to improve. But then, they also have their own ways in overcoming these kinds of difficulties. This only means that the participants are certainly aiming for improvement and they are working for it in their preferred techniques which they think they will learn better. Furthermore, they positively shared their inspirations to become an efficient writer. Majority of them stated that they are determined for their own good. Some are thinking for their future and they considered their profession as their inspiration. Also, few of them declared that they are inspired because of their professor, family and colleagues. Thus, the participants do not only rely on the teachings of their professors because they have this motivation to improve in writing by themselves.

\subsection{Implications for Practice}

Through this study, the researchers discovered that the fourth year criminology students are thinking for their future career. They want to prepare themselves and their skills especially in writing efficiently in order to be competent enough in their future job. Since English is now used as a language in terms of global trade, business and legal documents, the participants are enhancing their knowledge in vocabularies, sentence construction, and organization of ideas. They believe that being knowledgeable in writing is an immense quality that will definitely give them many opportunities.

However, the participants also declared about their difficulties in making a composition and what they did to overcome it by practicing regularly, asking for guidance and reviewing their output. This implies that the participants are helping themselves in order to enhance their skills in writing. In this way they can serve pompously to whatever task they are assigned to.

This study shows that to become proficient in English writing, students must not only rely on the lectures provided by the professors instead they should find a way to learn by themselves. Also, motivation plays a major role in pushing students to persevere in learning new ideas to be more productive member of the organization and community where they belong.

As future language professors, this study gave us awareness on the common difficulties of the students in writing and how to enhance their skills in writing. Since we are already aware of their common difficulties, we can easily determine the students' weak points when it comes to writing and eventually apply appropriate strategies in order to improve their writing skills.

Overall, the study implicates to the teaching strategies that teachers should employ to their students in order to meet their needs. Teachers must give more attention on vocabularies, spelling, grammar, and organization of ideas to supplement their knowledge and to equip them in their future responsibilities. Also, students should have more dedication to develop their confidence and abilities not only in writing but in communication as well. The University of Mindanao should also take part in providing seminars and workshops that will surely help cater the expected qualities of a true UM graduate.

\section{REFERENCES}

Anderson, N.J. (2003). Scrolling, clicking, and reading english: Online reading strategies in a second/foreign language. The Reading Matrix, 3(3).

Bradley, J. (1993). Methodological issues and practices in qualitative research. Library Quarterly, 63(4), 431-449. 
Cabansag,J.N. (2013).Written language proficiency of laboratory high school students in a state university in cagayan valley philippines. Researchers World-Journal of Arts, Science and Comerce. 4(2).

Coiro, J. (2003). Reading comprehension on the internet: Expanding our understanding of reading comprehension to encompass new literacies.

Deci, E. L., \& Ryan, R. M. (1985).Intrinsic motivation and self-determination in human behavior. New York: Plenum.

Eight tips to improve your english writing skills.(n.d.). Retrieved on July 1, 2015, from http $/ /$ englishtonight.com/8-tips-to-improved-english-writing-skills/.

English through films \& videos.(n.d.).Retrieved on June 30, 2015, from http://www2.caes.hku.hk/internet-resources/english-through-films/

Flower, L., \& Hayes, J. R. (1981). A Cognitive Process Theory of Writing. College Composition and Communication, 32(4), 365-87.

Gardner, R., and Lambert,W. (1972).Attitudes and motivation in second language learning. Rowley, Massachusetts: Newbury House.

Hayes, J. R., \& Flower, L. S. (1980). Identifying the organization of writing processes. In Lee W. Gregg \& Erwin R. Steinberg (Eds.), Cognitive Process in Writing (pp. 3-30). Hillsdale, NJ: Lawrence Erlbaum.

Jacobs, H. L., Zinkgraf, S.A., Wormouth, D.R., Hartfiel, V. F., \& Hughey, J. B. (1981).Testing ESL composition: A practical approach. Rowely, MA: Newbury House.

Jose, I. (1986). Police reports: A study of basic and investigative writing techniques in the Philippine setting. Philippine College of Criminology.

Kanar, C. (1998) Reading and writing confidence. Boston, New York: Houghton Mifflin Company.

Kitzinger, J. (1994). The methodology of focus groups: The importance of interactions between research participants. Social Health Illness 16:103-21.

Krashen, S. D. (1981). Bilingual education and second language acquisition theory. Schooling and language minority students: A theoretical framework, 51-79.

Kupper, L. (1989). Listening comprehension strategies in second language acquisition. Applied Linguistics, 10(4).

Langan, J. (2010). Exploring writing: Paragraphs and essays. New York: The McGraw-Hill Companies, Inc.

Leu, D. J., Jr. (2002). The new literacies: Research on reading instruction with the internet. In A. E. Farstrup\& S. J. Samuels (Eds.), What research has to say about reading instruction (3rd ed.) (pp. 310-336). Newark, DE: International Reading Association.

Lincoln, Y.S., \&Guba, E.G. (1985). Naturalistic inquiry. Beverly Hills, CA: Sage Publications.

McDonald, S., and Salomone, W. (1996) Reading-based writing. USA: Wadsworth Publishing Company.

Miller, L., and Whitehead, J., (2011) Report writing for criminal justice professionals. USA: Anderson Publishing.

Nine simple strategies for real-world english conversation practice.(n.d.). Retrieved June 30, 2015, from http://www.fluentu.com/english/blog/s imple-english- conversation-practice-online/

Pfeifer, H. L., \&Ferree, C. W. (2006). Tired of "reeding" bad papers? Teaching research and writing skills to criminal justice students. Journal of Criminal Justice Education, 17(1), 121-142.

Reep, D.,(2003)Technical writing: Principles, strategies and readings.USA: Pearson Education, Inc.

Roufa, T. (n.d.). Why writing skills are important in criminology. Retrieved January 10,2015,from http://criminologycareers.about.com/od/Education_and_Training/a/The-Written-Word-AndCriminlogy Careers.htm.

Ryan, R. M., \& Deci, E. L. (2000). Intrinsic and extrinsic motivations: Classic definitions and new directions. Contemporary educational psychology,25(1), 54-67.

San Jose, A. E. (2012). Linguistic experiences of adult dyslexic learners. UIC Research Journal, 18(1). 
Shank, G. D. (2002). Qualitative research: A personal skills approach. Prentice Hall.

The importance of learning english.(n.d.) Retrieved June 26, 2015, fromhttp:/inlinguamalta.com/ blog/the-importance-of-learning-english/.

Topping, K. (2003). Self and peer assessment in school and university: Realibility, validity and utility. In optimising new modes of assessment: In search of qualities and standards(pp.55-87). Springer Netherlands.

Wong, L. P. (2008). Focus group discussion: A tool for health and medical research. Singapore Med $J, 49(3), 256-60$.

Zhang, Y., \& Wildemuth, B. M. (2009). Qualitative analysis of content. Applications of social research methods to questions in information and library science, 308-319.

\section{AUTHORS' BIOGRAPHY}

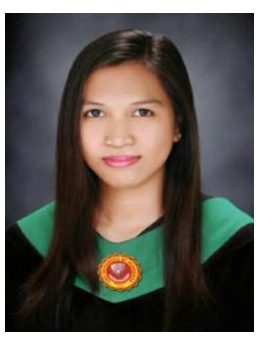

Rhealyn S. Guliman, is a graduate of Bachelor of Arts in English Language from the University of Mindanao - Matina Campus, Davao City class of 2016. She lives with her family at Km. 12, Sagrada Familia, Sasa, Davao City, Davao del Sur, Philippines. She was a consistent scholar of the City Government of Davao and had also served as a Student Assistant in their University for two academic years. In the academic year 2012-2014, she became a member of the official organization for the AB-English students - the University of Mindanao AB-English Students Society (UMABESS). On the following school year, she was elected as the official Business Manager of the organization which was renamed to University of Mindanao AB-English Association (UMABEA).

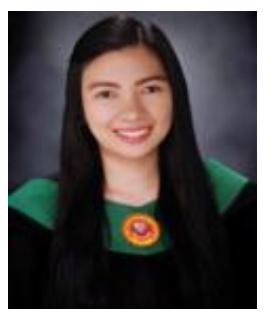

B aedido M. Timbang, is a graduate of Bachelor of Arts in English Language in the University of Mindanao. She is currently residing at Prk. 26 Muslim Vill., Times Beach, 76-A, Davao City, Davao del Sur, Philippines 8000. She can speak English, Filipino, Maguindanaon, and Bisaya. She also studied Arabic Language and Islamic Studies for four years in the Islamic Institution of Al- Madrasahtol AlArabiya. She was a member of University of Mindanao AB- English Society (UMABESS) from 2012-2014, then became the Vice President of the University of Mindanao AB-English Association (UMABEA) from 2014-2015. From 2015-2016 she retained her membership in the student organization of UMABEA.

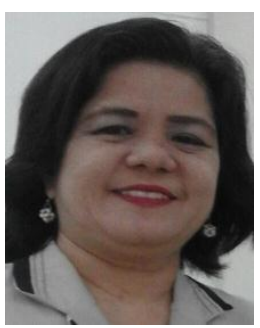

Ana Helena R. Lovitos, Ph.D., MedStud, English Lecturer \& Researcher, University of Mindanao Davao City Philippines. Graduate with the degree, Doctor of Philosophy in Applied Linguistics. Earned Master of Educational Studies at University of Newcastle, New South Wales Australia.

Writer of English Textbooks / Instructional Modules.

Peer Reviewer / Editor / Resource Speaker / Coach / Judge.

Author and Co-Author of Peer Reviewed and Published Journals.

Conference Organizer and Paper Presenter.

Member NUPSA / LNUAA / UICAA / PA3i / PAGE / PAFTE / PAIR / IRESInc. / REDTI 